\title{
Implicações clínicas e imunológicas da associação entre o HTLV-1 e a estrongiloidíase
}

\author{
Clinical and immunological consequences of the association \\ between HTLV-1 and strongyloidiasis
}

\author{
Maria Aurélia F. Porto' ${ }^{1}$, André Muniz¹, Jamary Oliveira Júnior ${ }^{1}$ \\ e Edgar Marcelino Carvalho ${ }^{1}$
}

\begin{abstract}
Resumo $A$ estrongiloidíase é uma das mais importantes helmintíases em países tropicais e estudos epidemiológicos têm demonstrado associação desta parasitose com o vírus HTLV-1. Em regiões onde estes dois agentes são endêmicos a coinfecção pode resultar no desenvolvimento de formas disseminadas da estrongiloidíase assim como em estrongiloidíase recorrente. Enquanto que o vírus HTLV-1 está relacionado com uma alta produção de IFN- $\gamma$ e desvio da resposta imune para o tipo Th1, a proteção contra helmintos está associada a uma resposta Th2. Devido a este viés da resposta imune, indivíduos infectados pelo HTLV-1 apresentam redução na produção de IL-4, IL-5, IL-13 e IgE, componentes participantes dos mecanismos de defesa contra S. stercoralis. Estas anormalidades constituem a base para a ocorrência de maior freqüência $e$ de formas mais graves da estrongiloidíase em pacientes infectados pelo HTLV-1.
\end{abstract}

Palavras-chaves: Estrongiloidíase. HTLV-1. Strongyloides stercoralis.

Abstract Strongyloidiasis is one of most important forms of helminthiasis in tropical countries and epidemiologic studies have shown the association of this parasitic disease with HTLV. It has been observed in regions where both these agents are endemic and coinfection may result in an increase in the disseminated forms of strongyloidiasis as well as recurrent strongyloidiasis. While HTLV-1 is related to a high production of IFN- $\gamma$ and deviation of the immune response towards a Th1 response, the protection against helminths is associated with Th2 like immune response. Individuals infected with HTLV and S. stercoralis have a reduction in the production of IL-4, IL-5, IL-13 and parasitic IgE response, all of which are factors participating in the defense mechanism against $\mathrm{S}$. stercoralis. These abnormalities are the basis for the occurrence of an increase in the severe forms of strongyloidiasis among patients infected with HTLV-1.

Key-words: Strongyloidiasis. HTLV-1. Strongyloides stercoralis.

A estrongiloidíase é uma das mais importantes helmintíases intestinais em países tropicais. Devido ao aumento de estrongiloidíase disseminada em conseqüência do grande uso de quimioterápicos e drogas imunossupressoras, tem ressurgido um interesse maior nesta helmintíase. Recentemente, tem sido demonstrada associação deste parasito com o vírus linfotrópico para células T humanas tipo 1 (HTLV-1), com apresentação de formas graves e recorrência após o tratamento. A transmissão da doença ocorre pela penetração das larvas filarióides infectantes (L3), através da pele humana intacta. As larvas migram para o pulmão pela corrente sangüínea. No pulmão, elas ultrapassam os capilares pulmonares e entram nos alvéolos, sofrendo uma muda para o estágio L4 neste órgão. Em seguida, elas ascendem até a faringe, são deglutidas e atingem a maturação final para verme adulto (fêmeas partenogenéticas) na mucosa do intestino delgado. Os ovos liberados atingem a maturidade e eclodem liberando as larvas rabditóides (L1) que migram para a luz do intestino. As larvas rabditóides nos estágios, L1 e L2, são eliminadas pelas fezes e podem transformar-se em vermes machos ou fêmeas de vida livre ou em larvas infectantes (L3). Um modo peculiar de infecção conhecida como auto-endoinfecção, ocorre pela transformação das larvas

\footnotetext{
1. Serviço de Imunologia do Hospital Universitário Prof. Edgard Santos da Universidade Federal da Bahia, Salvador, BA, Brasil. Trabalho financiado pelo Conselho Nacional de Pesquisa (CNPq).

Endereço para correspondência: Dr. Edgar M. Carvalho. Serviço de Imunologia/HUPES/ 5ªndar. R. João das Botas s/n, Canela, 40110-160 Salvador, BA, Brazil.

Tel: 5571 237-7353, Fax: 5571 245-7110

e-mail: imuno@ufba.br/edgar@ufba.br

Recebido para publicação em 26/11/2001.
} 
rabditóides em filarióides na luz intestinal, aumentando assim a carga parasitária. Esta auto-endo-infecção é responsável pela longa permanência do parasito no hospedeiro e o principal fator no desenvolvimento das formas graves da estrongiloidíase ${ }^{14}$.

Clinicamente, a estrongiloidíase pode se apresentar sob forma aguda e forma crônica, podendo esta última ser assintomática, sintomática ou grave, sendo que a maioria dos indivíduos infectados são assintomáticos ou oligosintomáticos. A forma aguda é pouco detectada em áreas endêmicas e as manifestações clínicas são decorrentes da penetração da larva na pele e da sua migração, causando uma erupção eritêmato-papulosa, pruriginosa, conhecida como larva currens. Além disso o paciente pode apresentar tosse não produtiva, febre, artralgia e cefaléia ${ }^{14} 1648$. A forma crônica pode ser leve, moderada ou grave. Quando é leve, geralmente é assintomática. Na forma moderada e grave há predomínio de manifestações digestivas, como dor abdominal, diarréia e vômitos, sendo estas manifestações mais intensas na forma disseminada, podendo levar à desidratação, distúrbios hidroeletrolíticos, hipoalbuminemia, e, em alguns casos, à íleo paralítico. Nestas formas graves da doença, o parasito pode ser documentado em vários órgãos como: fígado, pulmão, coração e sistema nervoso central (SNC). Complicações como infecções bacterianas (principalmente por germes gram negativos) podendo levar a um quadro de septicemia e meningite bacteriana, estão relacionadas com alta mortalidade. Nestes casos, há disseminação sangüínea de bactérias intestinais que acompanham as larvas durante o processo de auto-infecção. Alternativamente, lesões da mucosa do cólon podem facilitar a penetração das bactérias ${ }^{15}$.

A associação entre HTLV-1 e estrongiloidíase tem sido demonstrada em regiões onde ambos os agentes são endêmicos. Após relatos de casos isolados da associação entre HTLV-1 e infecção por S. stercoralis, estudos epidemiológicos têm sido realizadas em diversas localidades. Em Okinawa, uma área endêmica conhecida pela elevada freqüência de infecção pelo $S$. stercoralis e pelo HTLV-1, foi demonstrado que $60 \%$ de portadores de $S$. stercoralis apresentavam sorologia positiva para HTLV-140. Subseqüentemente Takai e cols. ${ }^{64}$ demonstraram índices de positividade para HTLV1 em $47,8 \%$ de pacientes com estrongiloidíase. Ainda em Okinawa anticorpos anti HTLV-1 foram detectados em $73,6 \%$ dos pacientes com estrongiloidíase, enquanto que em controles negativos para esta parasitose, anti HTLV-1 foi encontrado em somente $18,4 \%$ dos casos ${ }^{61}$. Não há, entretanto, unanimidade na demonstração de uma freqüência maior de infecção pelo $S$. stercoralis em pacientes infectados com o HTLV-1. Em estudo realizado em Okinawa não houve diferença entre a soropositividade para HTLV-1 (33,7\%) em 86 portadores de estrongiloidíase comparado com 29\% em 359 indivíduos controles negativos ${ }^{5}$. Embora um estudo realizado na Jamaica não tenha mostrado maior freqüência de anticorpos contra o $S$. stercoralis em pacientes HTLV-1 positivos comparados com HTLV-1 negativos ${ }^{42}$, houve associação significativa entre estas duas condições em um outro estudo nesta mesma região ${ }^{57}$. Em São Paulo, enquanto a estrongiloidíase foi observada em $12 \%$ dos portadores de HTLV-1, esta helmintíase só foi documentada em 1,6\% dos indivíduos negativos para este vírus ${ }^{18}$. Desta forma, existem fortes evidências da associação entre infecção pelo HTLV-1 e estrongiloidíase e dados que indicam que a presença destes dois agentes infecciosos em um mesmo indivíduo tem implicações clínicas e imunológicas. Formas graves da doença com evidência de hiperinfecção têm sido documentadas como também há relatos de estrongiloidíase recorrente em pacientes portadores de HTLV-1304344474950. Outro aspecto importante com relação a associação entre estas infecções é a maior falha terapêutica no tratamento da estrongiloidíase em pacientes portadores de HTLV-1. Enquanto que em 31 (94\%) de 33 pacientes com estrongiloidíase sem HTLV-1 foi observada a cura da parasitose após tratamento com tiabendazol, nos pacientes coinfectados, a cura foi documentada em somente $39(70 \%)$ de 55 pacientes tratados com esta mesma droga ${ }^{62}$. Adicionalmente foi observado que quando pacientes com estrongiloidíase foram tratados com ivermectina, o grupo resistente à droga apresentava soroprevalência de $80 \%$ para o vírus HTLV-1, enquanto que no grupo responsivo foi de $29,2 \%{ }^{63}$.

A maioria dos estudos com relação a resposta imune contra helmintos tem sido realizada em modelos experimentais e, nestes casos, existem evidências de que tanto a resposta celular como anticorpos, principalmente da classe IgE, participam da defesa contra helmintos. O mecanismo de defesa contra o $S$. stercoralis pode se dar através de respostas imunológicas que contribuam para expulsão das larvas juntamente com as fezes e, através de mecanismos de destruição do verme adulto ou das larvas durante a autoinfecção. Como em torno das larvas observa-se infiltração de eosinófilos ${ }^{28}{ }^{53}$, e como tem sido demonstrado que os grânulos liberados dos eosinófilos são tóxicos para as larvas infectantes (L3) de $S$. stercoralis ${ }^{60}$ tem sido aventada a possibilidade de que o mecanismo de citotoxidade celular dependente de anticorpo (ADCC) seja uma forma de defesa contra este helminto. Não só a elevação quantitativa de eosinófilos tem sido demonstrada nos pacientes infectados por helmintos, mas também um aumento da sua capacidade helmintotóxica ${ }^{20}$. A demonstração da ação citotóxica dependente de anticorpos, mediada pelos e o sinófilos contra os esquistossômulos in vitro, reforça a importância destas células no mecanismo de defesa contra helmintos 12132046

Enquanto níveis elevados de IgE total e IgE específica contra antígenos do parasita têm sido observados em pacientes assintomáticos e com forma leve da estrongiloidíase ${ }^{10} 35385159$, níveis baixos são 
observados na forma grave da doença ${ }^{27}$. A documentação de que animais infectados com Trichinella spiralis ou $S$. mansoni destroem estes parasitas com a participação de mastócito e IgE implicam que desgranulação de mastócitos é uma forma de defesa contra helmintos ${ }^{4}$. Tem sido também documentado que existe associação entre IgE contra antígeno de superfície de $S$. mansoni e resistência à reinfecção pelo S. mansoni21.

A descoberta de que a população de células $T$ auxiliadoras (CD4+) é heterogênea e constituída por subpopulações de células denominadas linfócitos $T$ auxiliadores do tipo 1 (Th1) e linfócitos T auxiliadores do tipo 2 (Th2), tem contribuido para um melhor entendimento da resposta imune nas doenças parasitárias. As células Th1 secretam interleucina-2 (IL-2), IFN- $\gamma$, fator de necrose tumoral-a (TNF- $\alpha$ ) e fator de necrose tumoral-b (TNF- $\beta$ ) e são responsáveis pela resposta imune celular, enquanto as células Th2 secretam IL-4, IL-5 e IL-10 e cooperam, predominantemente, com os linfócitos $B$ na produção de anticorpos $^{39}{ }^{58}$. Embora os mecanismos de defesa contra helmintos não sejam totalmente conhecidos, existem evidências de que a resposta Th2, através da síntese de IL-4, IL-5, e conseqüente produção de IgE, eosinofilia e mastocitose está envolvida na destruição do parasito. Em modelos experimentais há uma associação entre a resposta de células Th2 e a proteção contra diversos helmintos ${ }^{24}$. Interleucina-12 (IL-12) e IFN- $\gamma$ inibem a imunidade protetora contra estes parasitos ${ }^{2360}$. A produção de IL-4 é necessária para esta proteção, limita a gravidade da infecção e tem efeito redundante, pois interfere na resposta imune $e$ diretamente na fisiologia do intestino, aumentando o conteúdo de fluidos no trato digestivo. $\mathrm{O}$ acúmulo de fluidos é decorrente do aumento da permeabilidade intestinal e redução da absorção de líquidos ${ }^{24} 29$. Como a interleucina13 (IL-13) tem funções semelhantes à IL-4 e parece compartilhar do mesmo receptor ${ }^{9}$, esta citocina pode ter papel importante na eliminação de enteroparasitas como o S. stercoralis ${ }^{25}$.

O mecanismo de defesa na mucosa contra parasitos intestinais também é importante. A ligação de lgE contra antígeno parasitário à mastócito resulta em liberação de histamina que pode lesar diretamente estes parasitos, como também pode agir ativando e modulando a função de células lesivas para helmintos, como os eosinófilos ${ }^{41}$. Esta atividade de defesa local estaria dependente de linfócitos Th2, por produzirem substâncias como interleucina-3 (IL-3) e IL-4 que ativariam estes mastócitos. Estudo realizado com ratos hipotímicos revelou uma incapacidade dos mesmos em expulsar o S. ratti da mucosa intestinal; no entanto, após administração de IL-3, houve expulsão associada a intensa mastocitose ${ }^{12}$.

A infecção pelo HTLV-1 tem sido detectada em diferentes regiões do mundo, encontrando-se áreas endêmicas no Japão, África e América do Sul. Estudos epidemiológicos, realizados no Brasil, relataram a presença de anticorpos anti HTLV-1/2 em 0,41\% dos doadores de sangue, com variação entre $0,08 \%$ a
$1,35 \%$. A maior soroprevalência $(1,35 \%)$ foi encontrada na cidade de Salvador ${ }^{26}$. Clinicamente, a infecção pelo HTLV-1 pode manifestar-se sob a forma de leucemia/ linfoma de células T do adulto (ATL) e sob a forma de paraparesia espástica tropical (TSP) e mielopatia associada ao HTLV-1 (HAM) ${ }^{45}$. Existem relatos de outras doenças associadas ao HTLV-1, onde o vírus foi isolado nos órgãos alvos tais como: uveíte, polimiosite, artropatia inflamatória crônica, alveolite linfocítica, dermatite infectiva (em crianças) e outras doenças de origem autoimune ${ }^{33} 37$.

Sendo o HTLV-1 um vírus que tem predileção por infectar células $T$, são múltiplas as conseqüências da interação do HTLV-1 com o sistema imune. Sabe-se que o HTL̉-1 se beneficia com a ativação de células T, favorecendo uma infecção permanente. Estas células, quando infectadas, sofrem alterações importantes na expressão gênica e no controle do crescimento celular, tendo como conseqüência uma alta expressão de IL-2R, de IL-2 e de IL-15 $5^{76566}$. Embora a IL-2 seja o principal fator de proliferação de células $T$, nestes indivíduos infectados é a IL-15 que está relacionada com a imortalização de células T por inibir o processo natural de apoptose ${ }^{8}$. As células $T$ encontram-se sempre ativadas ${ }^{19}{ }^{33}$ e são evidências desta constante ativação a presença de marcadores como CD-25 e HLA-DR ${ }^{33}{ }^{36}$, a capacidade destas células de proliferar espontaneamente e de responder indiscriminadamente a estímulos sem restrição do HLA ${ }^{54}$. Como a proliferação é predominantemente de células T CD4+, a relação CD4/CD8 encontra-se aumentada. Tem sido também demonstrada uma expansão clonal de células T CD8+ em pacientes com HAM/TSP e em indivíduos assintomáticos relacionada a uma resposta citotóxica contra o vírus ${ }^{31}{ }^{34}$.

O perfil de citocinas secretadas por células de indivíduos assintomáticos infectados pelo HTLV-1 é mostrado na Figura 1. Embora comparando com controles tanto citocinas do tipo Th1 como Th2 estejam elevadas, nitidamente as citocinas mais elevadas em nossos pacientes são as relacionadas com o perfil Th1 (IFN- $\gamma$ e TNF- $\alpha$ ). Apesar da maior produção de IFN- $\gamma$ ser por células T CD4+ ${ }^{17}$ tem-se observado uma maior produção de IFN-g por células T CD8+ em pacientes com HAM/TSP quando comparada com a produção de IFN- $\gamma$ por células T CD8+ de indivíduos assintomáticos e controles sadios ${ }^{11}$. Estes dados sugerem que a desregulação da resposta de células $T$ na infecção pelo HTLV-1 está associada ao desenvolvimento de doenças como ATL e mielopatias .

Do ponto de vista imunológico, como a infecção pelo HTLV-1 se associa a uma resposta predominante Th1, com grande produção de IFN- $\gamma$, é de se esperar a existência de alteração da resposta humoral nestes pacientes, principalmente no que diz respeito à síntese de IgE. Como as células Th1 e Th2 secretam citocinas com funções antagônicas, existe uma modulação da ativação celular. Por exemplo, enquanto IL-4 e IL-10 diminuem a diferenciação da célula Th0 para Th1, a 


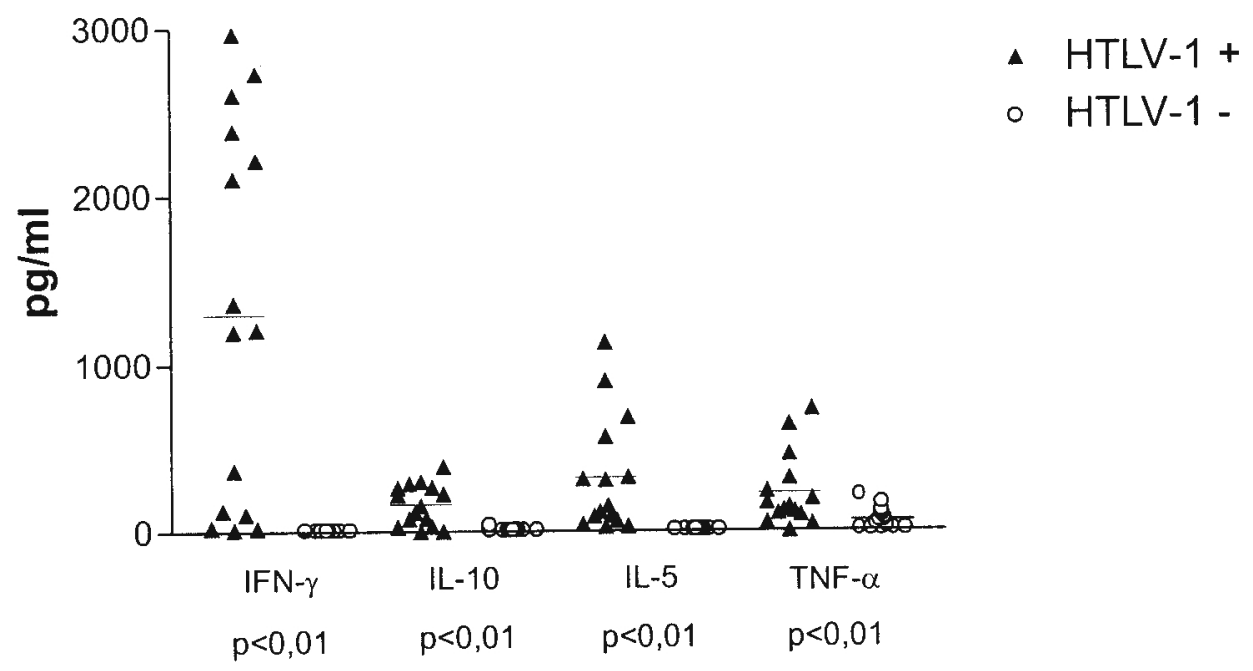

Figura 1-Perfil de citocinas (IFN-g, IL-5, IL-10 e TNF- $\alpha$ ) em sobrenadantes de culturas não estimuladas de células mononucleares de sangue periférico de 15 doadores de sangue com sorologia positiva para HTLV-1 e 15 indivíduos saudáveis.

produção de IFN- $\gamma$ modula negativamente a resposta Th2. De fato, níveis de IgE total e específico para antígeno de $S$. stercoralis são significativamente mais baixos em pacientes coinfectados com $S$. stercoralis e HTLV-1 do que em pacientes com estrongiloidíase sem HTLV-1324356. Além da redução da IgE total, redução de $\lg E$, IgA e IgG1 específicas contra $S$. stercoralis foi observado em 14 pacientes coinfectados por HTLV-1 e $S$. stercoralis, quando comparados com controles, pareados por idade e que apresentavam infecção isolada pelo $S$. stercoralis ${ }^{6}$. Mais recentemente, foi documentado diminuição dos níveis de IL-4 em culturas estimuladas com forbol ester (PMA) mais ionomicina e de IL-5 e IL-13 em culturas estimuladas com antígeno de S. stercoralis em pacientes coinfectados por HTLV-1 e S. stercoralis ${ }^{425}$. A Figura 2 mostra os níveis de IFN- $\gamma$, IL-5, IL-10 e IL-13 em sobrenadantes de culturas de células estimuladas com antígeno de S. stercoralis.

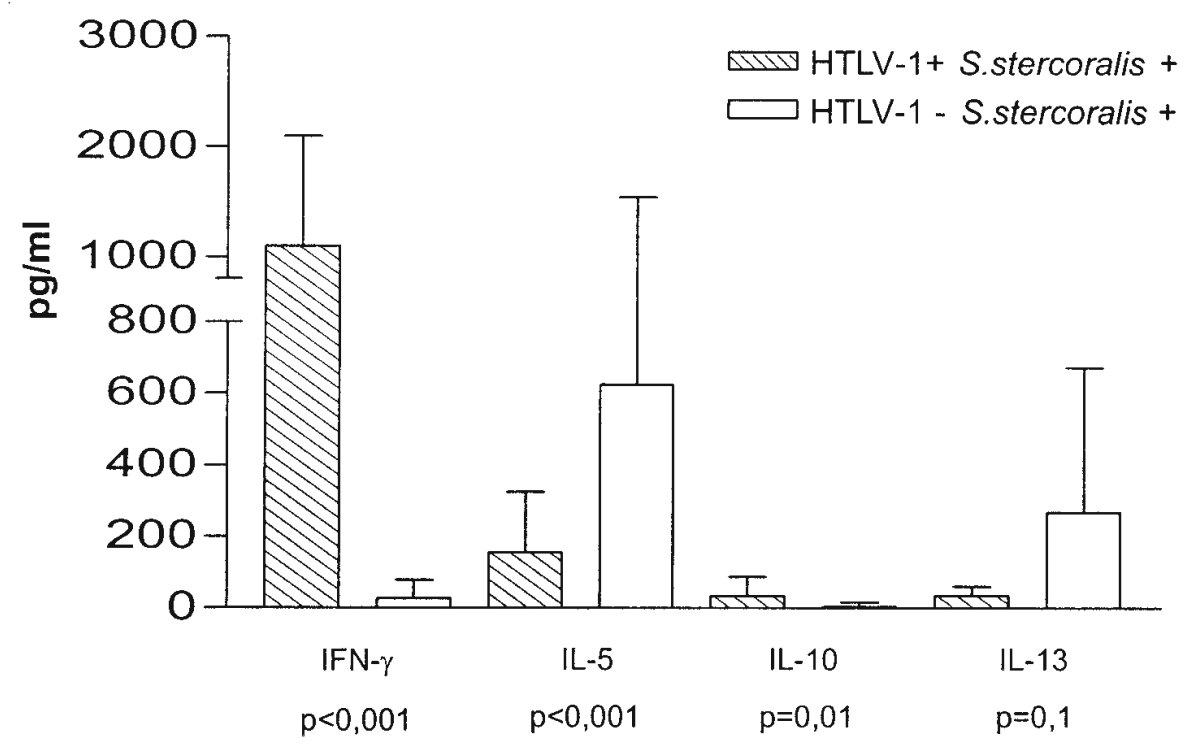

Figura 2 - Produção de IFN- $\gamma$, IL-5, IL-10 e IL-13 em culturas estimuladas com Ag. de S. stercoralis em 15 pacientes com estrongiloidíase coinfectados ou não (15) pelo HTLV-1. 
Enquanto pacientes co-infectados apresentam níveis bastante elevados de IFN- $\gamma$ estes pacientes apresentam níveis de IL-5 e IL-13 significantemente menores que pacientes infectados somente pelo $S$. stercoralis. A grande produção de IFN- $\gamma$ nestes pacientes diminue a secreção de lgE existindo uma correlação inversa entre a produção de IFN- $\gamma$ e IgE total e específica. Estes dados indicam que na infecção pelo HTLV-1 existe uma derivação da resposta imune para o tipo Th1 com aumento de IFN- $\gamma$ e diminuição de citocinas como IL-5, IL-4 e IL-13 que estão diretamente relacionadas com uma resposta Th2. Como a resposta imune contra helmintos tem sido relacionada com uma resposta Th2, a dimnuição de IL-4, IL-13, IL-5 e de imunoglobulinas da classe IgE constituem a base imunológica para a maior freqüência de estrongiloidíase em pacientes infectados por este vírus como também na patogênese da estrongiloidíase disseminada. Enquanto a redução de IL-4 e IL-13 favorecem a transformação das larvas rabditóides em filarióides e consequentemente ocorrência da autoinfecção, a redução de $\mathrm{IgE}$, de IL-5 e do número e da ativação de eosinófilos, diminuiria a destruição do parasito permitindo a sua passagem pela mucosa intestinal e penetração em vias sanguíneas (Figura 3).

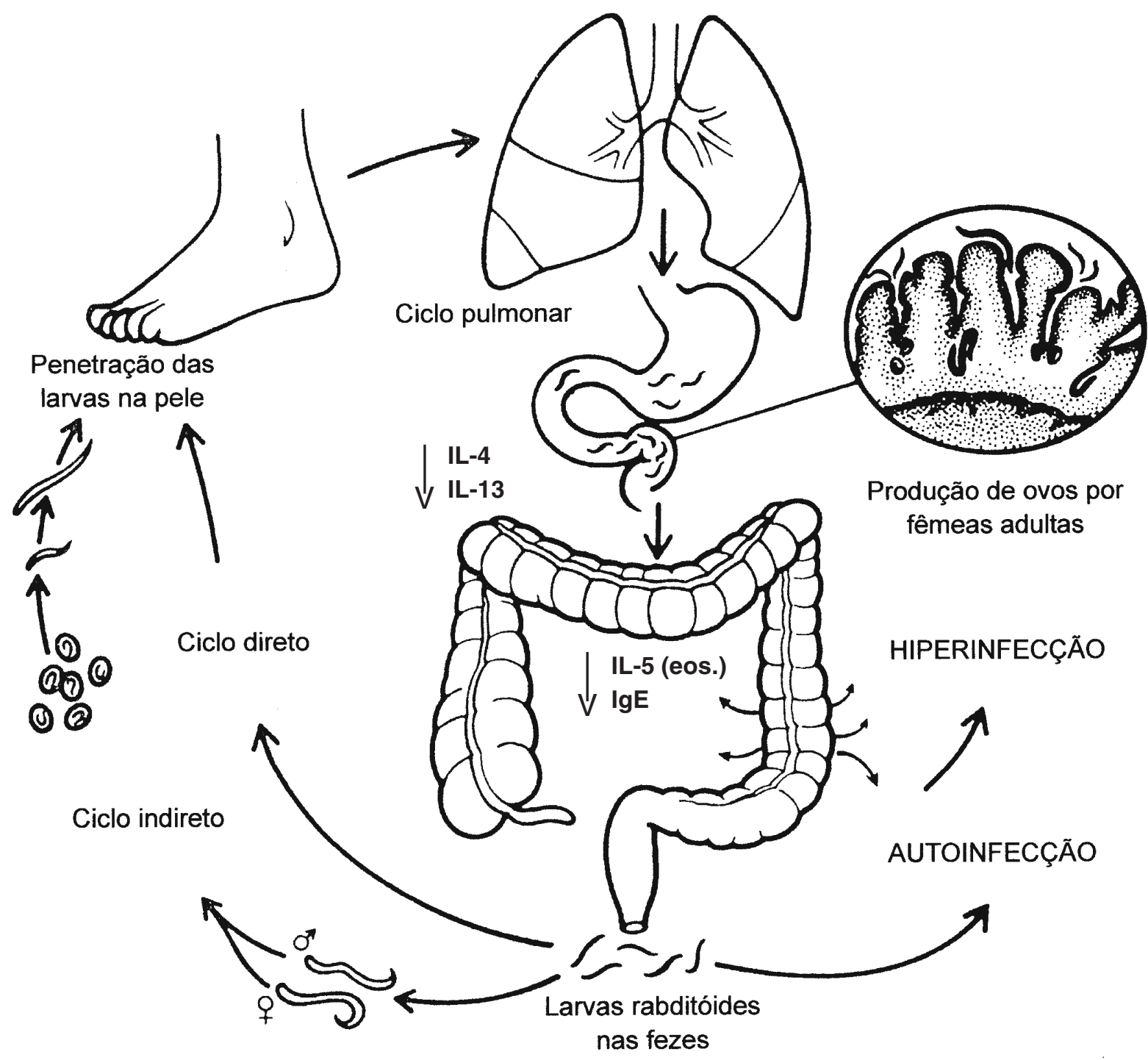

Figura 3 - Ciclo evolutivo do S. stercoralis com alterações imunológicas relacionadas com a infecção pelo HTLV (redução dos niveis de IL-4 e IL-13 a nivel intestinal podendo favorecer uma autoinfecção e dos níveis de IL-5 e lgE com conséquente alteração do processo de ADCC). 
A associação de formas graves da estrongiloidíase com o uso de corticosteróides, drogas imunossupressoras e neoplasias é bem conhecida na literatura. A realização do exame de Baermann antes e durante o uso de imunossupressores tem reduzido consideravelmente 0 aparecimento de formas disseminadas da estrongiloidíase no uso destas medicações. Nos últimos 10 anos, 08 indivíduos com forma grave da estrongiloidíase e $57 \mathrm{com}$ forma assintomática ou leve acompanhados no Hospital Universitário Professor Edgard Santos e no Hospital Santo Antônio em Salvador-Bahia foram avaliados com relação à produção de anticorpos IgG e lgE anti S. stercoralis, teste cutâneo e sorologia para HTLV-1 (Tabela1). Dos 08 pacientes com forma grave da estrongiloidíase, 06 eram infectados pelo HTLV-1 enquanto que no grupo assintomático ou com forma leve, apenas 01 tinha sorologia positiva para este vírus. Nenhum dos pacientes com forma grave apresentou positividade para o teste cutâneo e os níveis de IgE específico foram indetectáveis. Estes dados mostram a forte associação entre a infecção pelo HTLV-1 e disseminação do S. stercoralis, indicando que a infecção pelo HTLV-1 é no momento o principal fator predisponente para o desenvolvimento da estrongiloidíase grave em áreas de alta prevalência destas duas doenças.

Tabela 1- Conseqüências clínicas e imunológicas da associação entre estrongiloidíase e HTLV-1.

\begin{tabular}{|c|c|c|c|c|c|c|c|c|}
\hline \multirow[b]{4}{*}{ Formas clínicas da estrongiloidíase } & \multicolumn{8}{|c|}{ Aspectos imunológicos } \\
\hline & \multicolumn{4}{|c|}{ anticorpos anti S. stercoralis } & \multicolumn{2}{|c|}{ teste cutâneo positivo para S. stercoralis } & \multicolumn{2}{|c|}{ anticorpos anti HTLV-1 } \\
\hline & \multicolumn{2}{|c|}{$\lg G$} & \multicolumn{2}{|c|}{$\lg E$} & \multirow[b]{2}{*}{$\mathrm{n}^{\circ}$} & \multirow[b]{2}{*}{$\%$} & \multirow[b]{2}{*}{$\mathrm{n}^{\circ}$} & \multirow[b]{2}{*}{$\%$} \\
\hline & $\mathrm{n}$ & $\%$ & $\mathrm{n}$ & $\%$ & & & & \\
\hline Assintomático ou leve $(n=57)$ & 53 & 93 & 51 & 89 & 48 & 83 & 1 & 1,0 \\
\hline Grave $(n=8)$ & 8 & 100 & 0 & 0 & 0 & 0 & 6 & 75 \\
\hline
\end{tabular}

A maioria dos estudos previamente relatados apontam para a existência de uma associação entre S. stercoralis e HTLV-1. Há, também, evidências de que este vírus pode alterar a resposta imunológica do hospedeiro, permitindo a manutenção e aumento da carga parasitária favorecendo o aparecimento da estrongiloidíase grave. Se de um lado é claro que o HTLV-1 favorece ao aparecimento de formas graves da estrongiloidíase, estudos são necessários para determinar como o $S$. stercoralis muda o curso da infecção pelo HTLV-I. Em 1984 foi reportado um caso de um paciente com estrongiloidíase apresentando forma grave e recorrente da doença que após 2 anos de acompanhamento apresentou ATL, e foi confirmada a sorologia para HTLV-144. Foi sugerido, então, que o $S$. stercoralis agiria como cofator no desenvolvimento de ATL nos carreadores de HTLV-1, desde que uma integração monoclonal do vírus com anormalidades morfológicas dos linfócitos em sangue periférico conhecida como ATL forma smoldering foi demonstrada em $39 \%$ dos pacientes com estrongiloidíase coinfectados com HTLV-140. Um outro estudo mostrando que indivíduos com HTLV-1 coinfectados com $S$. stercoralis desenvolveram ATL mais previamente do que indivíduos apenas com HTLV-1, reforçou esta hipótese ${ }^{52}$. Apesar destes estudos sugerirem que o $S$. stercoralis pode acelerar o desenvolvimento de ATL, há relatos de que pacientes com ATL apresentam uma maior sobrevida e melhor resposta ao tratamento quimioterápico quando coinfectados pelo $S$. stercoralis quando comparados com pacientes com ATL sem infecção pelo S. stercoralis ${ }^{352}$. Estudos posteriores são necessários para avaliar se esta helmintíase pode interferir no desenvolvimento e no curso clínico das leucemias de células T.
Após a ATL, a mielopatia é a complicação mais grave da infecção pelo HTLV-1. Embora a literatura tenha registrado que manifestações clínicas associadas ao HTLV-1 ocorre em menos de $5 \%$ dos pacientes, trabalhos realizados no nosso serviço indicam que manifestações clínicas são bem mais freqüentes em pacientes infectados por este vírus. Por exemplo, enquanto impotência foi relatada em somente $2,9 \%$ dos doadores de sangue soronegativos, em pacientes com a infecção pelo HTLV-1 esta alteração foi relatada em $14,7 \%$ dos indivíduos recrutados em banco de sangue ${ }^{22}$. Em um estudo prospectivo com 149 indivíduos infectados pelo HTLV-1 e avaliados em um ambulatório específico, observamos uma freqüência elevada de sintomas caracterizados como: impotência $(18,1 \%)$, obstipação $(13,4 \%)$, alterações urinárias $(16,1 \%)$, parestesias $(27,5 \%)$, lombalgia $(18,8 \%)$ e espasticidade (14,7\%). Até o momento estudos não têm sido desenvolvidos com a finalidade de avaliar se parasitoses intestinais como estrongiloidíase podem através de uma resposta Th2 modular a resposta inflamatória e prevenir dano tecidual em pacientes infectados pelo HTLV-1. As observações preliminares realizadas por nós de que enquanto infecção por $S$. stercoralis foi documentada em $16 \%$ de indivíduos assintomáticos infectados pelo HTLV-1, este parasita só foi encontrado em $6 \%$ de 33 pacientes com HAM indicam, que estudos devem ser realizados no sentido de avaliar se as helmintiases com conseqüente produção de citocinas que modulam negativamente a resposta imunológica, estejam associadas com uma redução na freqüência e/ou gravidade das manifestações neurológicas em pacientes com HTLV-1. 


\section{REFERÊNCIAS BIBLIOGRÁFICAS}

1. Abe T, Nawa Y. Worm expulsion and mucosal mast cell response induced by repetitive IL-3 administration in Strongyloides rattiinfected nude mice. Immunology 63: 181-185, 1988.

2. Abe $T$, Sugaya $H$, Yoshymura $K$. Induction of the expulsion of Strangyloidis ratti and retention of Nippostrangyllus brasiliensis in athymic nude mice by repetitive administration of recombinant interleukin-3. Immunology 76: 10-14, 1992.

3. Agapé P, Copin MC, Cavrois M, Panelatti G, Plumelle Y, Ossondo Landeau M. Implication of HTLV-1 infection, strongyloidiasis, and P53 overexpression in the development, response to treatment, and evolution of non-Hodgkin's lymphomas in a endemic area (Martinique, French West Indies). Journal of Acquired Immune Deficiency Syndromes and Human Retrovirology 20: 394-402, 1999.

4. Ahmad A, Wang $\mathrm{CH}$, Bell RG. A role for IgE in intestinal immunity. Expression of rapid expulsion of Trichinella spiralis in rats transfused with IgE and thoracic duct lymphocytes. The Journal of Immunology 146: 3563-3570, 1991.

5. Arakaki T, Asato R, Ikeshiro T. Is the prevalence of HTLV-1 infection higher in Strongyloides carriers than in non-carriers? Tropical Medical Parasitology 43: 199-200, 1992.

6. Atkins NS, Lindo JF, Lee MG. Immunomodulatory Effects of Concurrent HTLV-I Infection in Strongyloidiasis. Journal of Acquired Immune Deficiency Syndromes and Human Retrovirology 18: 188-190, 1998.

7. Azimi N, Jacobson S, Leist T, Waldmann T. Involvement of IL-15 in the pathogenesis of Human T Lymphotropic Virus Type IAssociated Myelopathy/Tropical spastic Paraparesis: Implications for Therapy with a Monoclonal Antibody directed to the IL-2/15Rb Receptor. The Journal of Immunology 163: 4064-4072,1999.

8. Azimi N, Nagai M, Jacobson S, Waldmann TA. IL-15 plays a major role in the persistence of Tac-specific CD8 cells in HAM/TSP patients. Proceedings of the National Academy of Science 98: 14559-14564, 2001

9. Barner M, Mohrs M, Brombacher F, and Kopf M. Differences between IL-4Ra-deficient and IL-4-deficient mice reveal a role for IL-13 in the regulation of Th2 responses. Current Biology 8: 669-672, 1998.

10. Bezjak B. Immunoglobulin Studies in Strongyloidiasis with Special Reference to Raised Serum IgE Levels. The American Journal of Tropical Medicine and Hygiene 24: 945-947, 1975.

11. Biddison WE, Kubota R, Kawanishi T. Human $T$ Cell Leukemia Virus Type I (HTLV-I)-Specific CD8 ${ }^{+}$CTL Clones from Patients with HTLV-I-Associated Neurologic Disease Secrete Proinflammatory Cytokines, Chemokines, and Matrix Metalloproteinase. The Journal of Immunology 159: 2018-2025, 1997.

12. Butterworth AE, Sturrock RF, Houba V. Antibody-dependent cellmediated damage to schistosomula in vitro. Nature 252: 503505, 1974.

13. Capron M, Rousseaux J, Mazingue C. Rat Mast Cell-Eosinophil Interaction in Antibody-Dependent Eosinophil Cytotoxicity to Schistosoma mansoni Schistosomula. The Journal of Immunology 121: 2518-2524, 1978.

14. Carvalho EM. Strongyloidiasis. Clinics in Gastroenterology 7: 179200, 1978

15. Carvalho EM. Helminthic enteropathies. Baillière's Clinical Tropical Medicine Communicable Diseases 3: 537-565, 1988.
16. Carvalho EM, Bacellar O, Porto MAF, Santos SB, Galvão-Castro B, Neva FA. Cytokine profile and immunomodulation in asymptomatic HTLV-1 infected blood donors. Journal of Acquired Immune Deficiency Syndromes and Human Retrovirology 26:1-6, 2001.

17. Carvalho EM, Gomes MC, Rocha, H. Septicemia por gram negativos em portadores de Estrongiloidíase grave. Revista Médica da Bahia 26: 15-19, 1980.

18. Chieffi PP, Chiattone CS, Feltrim EM, Alves RC. Coinfection by Strongyloides stercoralis in blood donors infected with human Tcell leukemia/lymphoma virus type 1 in São Paulo city, Brazil. Memórias do Instituto Oswaldo Cruz 95: 711-712, 2000.

19. Copeland-Karen FT, Heeney-Jonathan LT. Helper Cell Activation and Human Retroviral Pathogenesis. Microbiological Reviews 60: 722-742, 1996.

20. David JR, Vadas MA, Butterworth AE. Enhanced Helminthotoxic Capacity of Eosinophils from Patients with Eosinophilia. The New England Journal of Medicine 303: 1147-1152, 1980.

21. Dunne DW, Butterworth AE, Fulford AJ, Ouma JH, Sturrock RF. Human IgE responses to Schistosoma mansoni and resistance to reinfection. Memórias do Instituto Oswaldo Cruz 87: 99-103, 1992.

22. Farias D, Machado MC, Rodrigues BMC, Campos I, Farias SN, Melo A. HTLV-I/II Infection and Erectile Insufficiency in Bahia, Brazil. AIDS Research and Human Retroviruses 17: S-66, 2001.

23. Finkelman FD. Effects of interleukin 12 on immune responses and host protection in mice infected with intestinal nematode parasites. Journal of Experimental Medicine 179: 1563-1572, 1994.

24. Finkelman FD, Donohue TS, goldhill J. Cytokine Regulation of Host Defense Against Parasitic Gastrointestinal Nematodes. Annual Review of Immunology 15: 505-533, 1997.

25. Finkelman FD, Wynn TA. The role of IL-13 in helminth-induced inflammation and protective immunity against nematode infections. Current Opinion of Immunology 11: 420-426, 1999.

26. Galvão CB, Loures L, Rodrigues LGM. Geographic distribution of human T-lymphotropic virus type-I among blood donors: a Brazilian nationwide study. Transfusion 37: 242, 1997.

27. Genta RM, Douce RW, Walzer PD. Diagnostic Implications of Parasite-Specific Immune Responses in Immunocompromised Patients with Strongyloidiasis. Journal of Clinical Microbiology 23: 1099-1103, 1986.

28. German JC, Flores JH, Chiesura G. Estrongiloidiasis Fatal en Paciente Inmunodeprimido Pos-Transplante Renal. Revista do Hospital das Clínicas da Faculdade de Medicina de São Paulo 47: 31-33, 1992.

29. Goldhill J, Morris SC, Maliszewski C, Urban Jr JF, Funk CD, Finkelman FD, Shea-Donohue T. Interleukin-4 modulates cholinergic neural control of mouse small intestinal longitudinal muscle. American Journal Physiology 272:G1135-G1140, 1997.

30. Gotuzzo E, Terashima A, Alvarez H. Strongyloides stercoralis Hyperinfection Associated with Human T Cell Lymphotropic Virus Type-1 Infection in Peru. The American Journal of Tropical Medicine and Hygiene 60: 146-149, 1999.

31. Hanon E, Hall S, Taylor GP, Saito M, Davis R, Tanaka Y, Usuku $\mathrm{K}$, Osame M, Weber $\mathrm{J}$ and Banghan CRM. Abundant Tax protein expression in CD4+ T cells infected with human T-cell lymphotropic virus type I (HTLV-I) is prevented by cytotoxic T lymphocytes. Blood 95: 1386-1392, 2000. 
32. Hayashi J, Kishihara Y, Yoshimura E, Furusyo N, Yamaji K, Kawakami T, Murakami H, Kashiwagi S. Correlation between human T cell lymphotropic virus type-1 and Strongyloides stercoralis infections and serum immunoglobulin $E$ responses in residents of Okinawa, Japan. The American Journal of Tropical Medicine and Hygiene 56: 71-75, 1997.

33. Höllsberg P, Hafler DA. Pathogenesis of Diseases Induced by Human Lymphotropic Virus Type I Infection. Seminars in Medicine of the Beth Israel Hospital, Boston 328: 1173-1182, 1993.

34. Kubota R, Kawanishi T, Matsubara H. Demonstration of Human T Lymphotropic Virus Type I (HTLV-I) Tax-Specific CD8+ Lymphocytes Directly in Peripheral Blood of HTLV-I-Associated Myelopathy/ Tropical Spastic Paraparesis Patients by Intracellular Cytokine Detection. The Journal of Immunology 161: 482-488, 1998.

35. Leão RC, Barros MM, Mendes E. Immunological study of human strongyloidiasis. I. Analysis of IgE levels. Allergology Immunopathology 8: 31-34, 1980.

36. Macchi B, Grelli S, Matteucci C. Human Th1 and Th2 T-cell clones are equally susceptible to infection and immortalization by human T-lymphotropic virus type I. Journal of General Virology 79: 24692474, 1998.

37. Mattos K, Queiroz C, Peçanha-Martins AC. Lymphocyte Alveolitis in HAM/TSP Patients. Arquivos de Neuropsiquiatria 51: 134-136, 1993.

38. Mcrury J, Messias IT, Walzer PD. Specific IgE responses in human strongyloidiasis. Clinical Experimental Immunology 65: 631-638, 1986.

39. Mosmann TR, Cherwinski H, Bond MW, Giedlin MA, Coffman RL. Two types of murine helper T cell clone. Definition according to profiles of lymphokine activities and secreted proteins. The Journal of Immunology 136: 2348-2357, 1986.

40. Nakada K, Kohakura M, Komoda H, Hinuma Y. High incidence of HTLV antibody in carriers of Strongyloides stercoralis. Lancet 1: 633, 1984.

41. Nawa $Y$, Ishikava N, Tsuchiya K. Selective effector mechanisms for the expulsion of intestinal helminths. Parasite Immunology 16: 333-338, 1994.

42. Neva FA, Oliveira J, Gam AA. Interferon-g and Interleukin-4 Responses in Relation to Serum IgE Levels in Persons Infected with Human T Lymphotropic Virus Type I and Strongyloides stercoralis. Journal of Infectious Diseases 178: 1856-1859, 1998.

43. Newton RC, Limpuangthip P, Greenberg S. Strongyloides stercoralis Hyperinfection in a Carrier of HTLV-I Virus With Evidence of Selective Immunosuppression. The American Journal of Medicine 92: 202-207, 1992.

44. O'Doherty MJ, Van de Pette, JE. Nunan TO, Croft DN. Recurrence Strongyloides stercoralis Infection in a Patient with T-Cell Lymphoma-Leukemia. Lancet 1: 858, 1984.

45. Osame M, Usuaki K, Izumo S. HTLV-1 associated myelopathy, a new clinical entity. Lancet 1: 1031-1032, 1986.

46. Ottesen EA, Stanley AM, Gelfand JA. Immunoglobulin and Complement Receptors on Human Eosinophils and Their Role in Cellular Adherence to Schistosomules. The American Journal of Tropical Medicine and Hygiene 26: 134-141, 1977.

47. Pagliuca A. Strongyloides hyperinfection in adult T-cell leukaemia/ lymphoma. British Journal of Haematology 105:1, 1999.
48. Patey O, Bouhali R, Breuil J. Arthritis Associated with Strongyloides stercoralis. Scandinavian Journal of Infectious Diseases 22: 233-236, 1990.

49. Patey O, Gessain A, Breuil J, Courillon-Mallet A, Daniel MT, Miclea JM, Roucayrol AM, Sigaux F, Lafaix C. Seven years of recurrent severe strongyloidiasis in an HTLV-I-infected man who developed adult T-cell leukaemia. Journal of Acquired Immune Deficiency Syndromes and Human Retrovirology 6: 575-579, 1992.

50. Phelps KR, Ginsberg SS, Cinningham AW, Tschachler E, Dosik $\mathrm{H}$. Case report: adult $\mathrm{T}$ - cell leukemia/lymphoma associated with recurrent Strongyloides hyperinfection. The American Journal of the Medical Sciences 302: 224-228,1991.

51. Pires ML, Dreyer G. Revendo a Importância do Strongyloides stercoralis. Revista do Hospital das Clínicas da Faculdade de Medicina de São Paulo 48:175-182, 1993.

52. Plumelle $\mathrm{Y}$, Gonin C, Edouard A, Bucher BJ, Thomas L, Brebion A, Panelatti G. Effect of Strongyloides stercoralis infection and eosinophilia on age at onset and prognosis of adult T-cell leukemia. The American Journal of Clinical Pathology 107:81-87, 1997.

53. Poltera AA, Katsimbura N. Granulomatous Hepatitis due to Strongyloides Stercoralis. Journal of Pathology 113: 241-245, 1974.

54. Popovic M, Flomenberg N, Volkman DJ. Alteration of T-Cell Functions by Infection with HTLV-I or HTLV-II. Science 226: 459462, 1984.

55. Porto MAF, Neva FA, Lisboa W, Thompson R, Alcântara L, Carvalho EM. HTLV-1 decreases Th2 type of immune response in patients with strongyloidiasis. Parasite Immunology 23: 503507, 2001.

56. Porto MAF, Oliveira Filho J, Neva FA, Orge G, Alcântara L, Gam A, Carvalho EM. Influence of HTLV-1 infection on the serological and Skin Test for strongyloidiasis. The American Journal of Tropical Medicine Hygiene 65: 610-613, 2001.

57. Robinson RD, Lindo JF, Neva FA, Gam AA, Vogel P, Terry SI, Cooper ES. Immunoepidemiologic studies of Strongyloides stercoralis and human T lymphotropic virus type I infections in Jamaica. Journal of Infectious Diseases 169: 692-696, 1994.

58. Romagnani S. Type $1 \mathrm{~T}$ helper and type $2 \mathrm{~T}$ helper cells: functions, regulation and role in protection and disease. International Journal of Clinical Laboratory Research 21: 152-158, 1992.

59. Rossi CL, Takahashi EEH, Partel CD. Total Serum IgE and Parasite-Specific IgG and IgA Antibodies in Human Strongyloidiasis. Revista do Instituto de Medicina Tropical de São Paulo 35: 361-365, 1993.

60. Rotman HL, Schnyder-Candrian S, Scott P, Nolan TJ, Schad G.A, Abraham D. IL-12 eliminates the Th-2 dependent protective immune response of mice to larval Strongyloides stercoralis. Parasite Immunology 19:29-39, 1997.

61. Sato Y, Shiroma Y. Concurrent Infections with Strongyloides and T-Cell Leukemia Virus and Their Possible Effect on Immune Responses of Host. Clinical Immunology and Immunopathology 52: 214-224, 1989.

62. Sato Y, Shiroma Y, Kiyuna S, Toms H, Kobayashi J. Reduced efficacy of chemotherapy might accumulate concurrent HTLV-I infection among strongyloidiasis patients in Okinawa, Japan. Transactions of the Royal Society Tropical Medicine and Hygiene 88: 59, 1994. 
63. Shikiya K, Zaha O, Niimura S, Uehara T, Ohshiro J, Kinjo F, Saito A, Asato R. Clinical study on ivermectin against 125 strongyloidiasis patients. Kansenshogaku Zasshi 68: 13-20, 1994.

64. Takai A, Uesato H, Nakama T, Sato Y. Otsuru, M. Jpn. J. Parasitol., $33: 33,1984$. Apud: Sato Y. \& Shiroma Y. Concurrent Infections with Strongyloides and T-Cell Leukemia Virus and Their Possible Effect on Immune Responses of Host. Clinical Immunology and Immunopathology 52: 214-224, 1989.

65. Tendler CL, Greenberg SJ, Blatner WA, Mann A, Murphy E, Fleisher T, Hanchard B, Morgan O, De Burton J, Nelson DL,
Waldmann T. Transactivation of interleukin 2 and its receptor induces immune activation of human T-cell lymphotropic virus type I associated myelopathy: pathogenic implications and a rationale for immunotherapy. Proceedings of the National Academy of Science, USA 87: 5218-5222, 1990.

66. Uchiyama T, Hori T, Tsudo M, Wano Y, Umadome H, Tamori S, Yodoi J, Maeda M, Sawami H, Uchino H. Interleukin-2 receptor (Tac antigen) expressed on adult T-cell leukemia cells. Journal of Clinical Investigation 76: 446-453, 1985. 